The University of Maine

\title{
DigitalCommons@UMaine
}

Earth Science Faculty Scholarship

Earth Sciences

$3-22-2007$

\section{In Situ Monitoring of Free-Phase Gas Accumulation and Release in Peatlands Using Ground Penetrating Radar (GPR)}

\author{
Xavier Comas \\ Lee Slater \\ Andrew S. Reeve \\ University of Maine - Main, asreeve@maine.edu
}

Follow this and additional works at: https://digitalcommons.library.umaine.edu/ers_facpub

Part of the Earth Sciences Commons

\section{Repository Citation}

Comas, Xavier; Slater, Lee; and Reeve, Andrew S., "In Situ Monitoring of Free-Phase Gas Accumulation and Release in Peatlands Using Ground Penetrating Radar (GPR)" (2007). Earth Science Faculty Scholarship. 52.

https://digitalcommons.library.umaine.edu/ers_facpub/52 


\title{
In situ monitoring of free-phase gas accumulation and release in peatlands using ground penetrating radar (GPR)
}

\author{
Xavier Comas, ${ }^{1}$ Lee Slater, ${ }^{2}$ and Andrew Reeve ${ }^{1}$ \\ Received 6 December 2006; revised 16 February 2007; accepted 23 February 2007; published 22 March 2007.
}

[1] We tested a set of surface common mid-point (CMP) ground penetrating radar (GPR) surveys combined with elevation rods (to monitor surface deformation) and gas flux measurements to investigate in-situ biogenic gas dynamics and ebullition events in a northern peatland (raised bog). The main findings are: (1) changes in the two-way travel time from the surface to prominent reflectors allow estimation of average gas contents and evolution of freephase gas (FPG); (2) peat surface deformation and gas flux measurements are strongly consistent with GPR estimated changes in FPG content over time; (3) rapid decreases in atmospheric pressure are associated with increased gas flux; and (4) single ebullition events can induce releases of methane much larger (up to $192 \mathrm{~g} / \mathrm{m}^{2}$ ) than fluxes reported by others. These results indicate that GPR is a useful tool for assessing the spatial distribution, temporal variation, and volume of biogenic gas deposits in peatlands. Citation: Comas, X., L. Slater, and A. Reeve (2007), In situ monitoring of free-phase gas accumulation and release in peatlands using ground penetrating radar (GPR), Geophys. Res. Lett., 34, L06402, doi:10.1029/2006GL029014.

\section{Introduction}

[2] Northern peatlands are an important component of the global carbon (C) cycle, accounting for 5 to $10 \%$ of methane $\left(\mathrm{CH}_{4}\right)$ flux to the atmosphere while acting as a net sink for atmospheric carbon dioxide $\left(\mathrm{CO}_{2}\right)$ [e.g., Charman, 2002]. Studies related to greenhouse gas emission from peatlands and their response to climate change have increased significantly during recent years [e.g., Gorham, 1991; Waddington et al., 1998]. Release of freephase gas (FPG) in peatlands occurs by diffusion, wicking through vascular plants, or episodic ebullition events that can release large volumes of gas over a short time scale (e.g., $35 \mathrm{~g} \mathrm{CH} 4 / \mathrm{m}^{2}$ in minutes or hours, Glaser et al. [2004]). The main processes proposed to trigger ebullition are: (1) episodes of low atmospheric pressure inducing amplified gas bubble volume and increased buoyancy [e.g., Fechner-Levy and Hemond, 1996; Rosenberry et al., 2003; Glaser et al., 2004; Tokida et al., 2005a]; and (2) internal processes that result in unstable over-pressuring of FPG [Romanowicz et al., 1995; Glaser et al., 2004; Comas et al., 2005a].

[3] Estimated FPG volumes in peatlands range from 0 to $19 \%$ of peat volume (see Rosenberry et al. [2006] for

\footnotetext{
${ }^{1}$ Department of Earth Sciences, University of Maine, Orono, Maine, USA.

${ }^{2}$ Department of Earth and Environmental Sciences, Rutgers University, Newark, New Jersey, USA.
}

Copyright 2007 by the American Geophysical Union. 0094-8276/07/2006GL029014 review). Most of these estimates involve in situ methodologies limited by: (1) destructive sampling and/or invasive insertion of probes, such as time domain reflectometry (TDR) [Beckwith and Baird, 2001], capacitance soil moisture probes [e.g., Kellner et al., 2005; Tokida et al., 2005b], piezometers [Rosenberry et al., 2003], or deformation sensor rods [Price, 2003]; or (2) small scale non-destructive techniques that offer little or no information about spatial distribution of FPG in peat, such as gas chamber techniques, or surface deformations using GPS [Glaser et al., 2004].

[4] Ground penetrating radar (GPR) is a widely used tool for non-invasively measuring soil water content from soil layers [e.g., Hubbard et al., 2002; Huisman et al., 2003] in the vadose zone. The common mid-point method (CMP) is an extensively used technique for determining subsurface velocity $(v)$ from radar reflections that requires no prior knowledge of the subsurface (e.g., depth to reflectors) [Greaves et al., 1996]. In CMP acquisition, the distance between antennas is increased stepwise while keeping a common mid-point (e.g., Figure 1). CMP data can yield information about the 1D electromagnetic (EM) velocity structure midway between the transmitter and the receiver [Hubbard et al., 2002]. The difference between travel time $(t)$ at a given antenna offset $(x)$ and that time $\left(t_{0}\right)$ for zero offset $(x=0)$ is called normal moveout (NMO). As the difference in $t$ to a particular reflector changes with $x$, acquired data represent a 1D EM $v$ structure midway between transmitter and receiver to the depth of that particular reflector (e.g., Figure 2). This approach is considered valid for dips of reflectors in the line of the survey smaller than $15^{\circ}$ [e.g., Neal, 2004].

[5] GPR has been previously used in FPG-related studies in peatlands and peat soils using acquisition modes other than CMP, such as zero offset profiling between boreholes [Comas et al., 2005a], or common offset surveys [Comas et al., 2005b; Comas and Slater, 2007]. In all cases GPR was used to measure the same soil water content proxy (e.g., dielectric permittivity) at different spatial scales. The large changes in gas content (and therefore moisture content) driven by ebullition events in peatlands forms the basis for using EM wave velocity to determine gas content in peat soils. Following the laboratory results reported by Comas and Slater [2007], the objective of our study was to investigate the feasibility of using surface based GPR as an entirely non-invasive method for monitoring ebullitiondriven changes in FPG within the bulk peat profile at the field scale. The major advantages of the method, relative to probe-based (e.g., TDR) methods, for measuring gas contents are (1) instruments do not need to be inserted into the peat soil, avoiding the artificial creation of preferential gas release pathways, and (2) a larger volume of peat is sampled, providing a more representative estimate for 


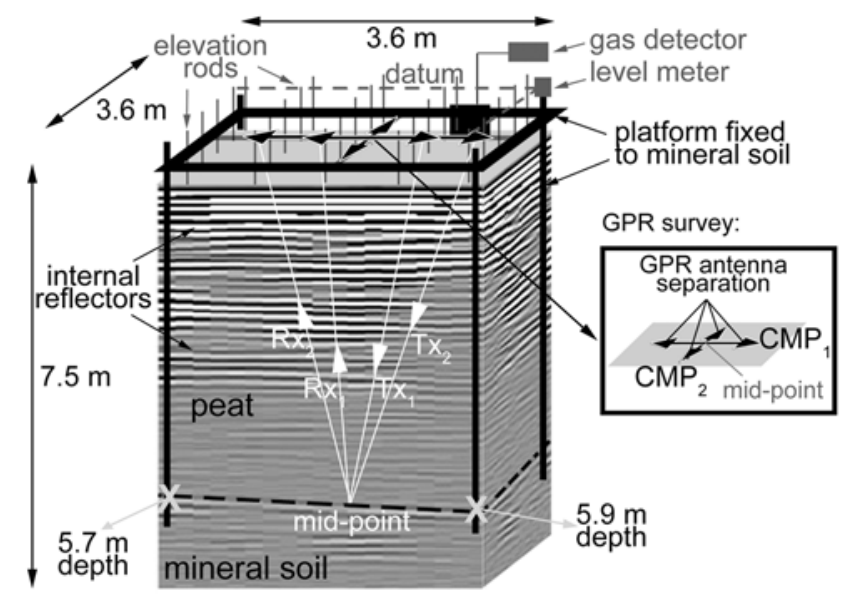

Figure 1. Instrumentation setup in the field showing: platform fixed to mineral soil, GPR survey (showing examples of transmitter [Tx] and receiver [Rx] antenna pathways through internal reflectors, and schematic of common midpoint [CMP] gather), elevation rods, and portable gas detector. Shown depths to mineral soil were confirmed with direct core sampling. (inset) Orientation of $\mathrm{CMP}$ gathers $\left(\mathrm{CMP}_{1}\right.$ and $\left.\mathrm{CMP}_{2}\right)$.

FPG in the bulk peat profile. Results from the GPR data are compared with atmospheric pressure measurements to further evaluate this method for monitoring FPG in peatlands.

\section{Experimental Field Design and Methodology}

[6] A time-series of surface GPR measurements in the CMP acquisition mode were conducted over a $3.6 \mathrm{~m} \times$ $3.6 \mathrm{~m}$ area at Caribou Bog (multi-unit peatland located near Bangor, Maine) to detect areas with contrasts in the EM wave velocity over time. A platform anchored in the mineral soil (5.7-5.9 $\mathrm{m}$ depth) was constructed to provide a fixed frame of reference and to avoid disturbance of the peat surface while collecting data (Figure 1). The GPR measurements were coupled with surface deformation measurements using elevation rods (relative to the platform) and gas flux estimates using a static chamber set at the ground surface and attached to a portable combustible gas detector (Figure 1). The study site (located next to a pool in the central unit of Caribou Bog) was chosen based on observations of significant gas accumulation during previous fieldwork conducted in the area [e.g., Comas et al., 2005b].

[7] All GPR measurements were collected with a MalaRAMAC system using $100 \mathrm{MHz}$ antennas. Two sets of orthogonal $3.6 \mathrm{~m}$ CMP gathers (line $1\left[\mathrm{CMP}_{1}\right]$ and line 2 $\left[\mathrm{CMP}_{2}\right]$ in Figure 1) with $20 \mathrm{~cm}$ offset intervals were acquired. The spacing between traces was $0.1 \mathrm{~m}$ and maximum stacking (2,048 stacks per trace) was used to optimize the strength of the returned signal. A $550 \mathrm{~ns}$ sampling time window was adequate to capture the reflection from the peat-mineral soil contact (Figure 2a). Basic processing routine was limited to: (1) a "dewow" filter; (2) a time-varying gain; and (3) a time-zero static correction. Velocities were measured by picking $t$ at the peak of the first side-lobe of the reflected wavelet corresponding to the mineral soil reflector (Figure 2a). Using a least squares routine, travel times $\left(t_{x}\right)$ were fit with a NMO hyperbola using equation 1 (see Figure 2b),

$$
t_{x}^{2}=\frac{x^{2}}{v^{2}}+t_{0}^{2},
$$

where $x$ is the separation (offset) between antennas, $v$ is the EM wave velocity, and $t_{0}$ is the zero-offset reflection time. In order to estimate gas content from EM wave velocities we applied the Complex Refractive Index Model (CRIM) [e.g., Huisman et al., 2003], which is a volumetric mixing model for the soil [Wharton et al., 1980] as shown in equation 2 :

$$
\left(\varepsilon_{r(b)}\right)^{\alpha}=\left(\theta \varepsilon_{r(w)}\right)^{\alpha}+\left((1-n) \varepsilon_{r(s)}\right)^{\alpha}+\left((n-\theta) \varepsilon_{r(a)}\right)^{\alpha}
$$

where $\varepsilon_{r(a)}, \varepsilon_{r(w)}$, and $\varepsilon_{r(s)}$ are the relative dielectric permittivity of gas (1), water $\left(80\right.$ at $\left.21^{\circ} \mathrm{C}\right)$ and the soil particles respectively, $n$ is the porosity, $\theta$ is the volumetric soil water content and $\alpha$ is a factor accounting for the orientation of the electrical field and the geometrical arrangement of minerals (typically 0.35 for peat soils, Kellner et al. [2005]). Gas content estimation using the CRIM considered: (1) $0.5 \%$ changes in porosity [e.g., Kellner et al., 2005] as a function of time due to peat surface deformation (using final porosity values of $92.5 \%$, Comas et al. [2005a]); (2) $\varepsilon_{r(w)}=80$ at $21^{\circ} \mathrm{C}$, as recorded temperature variation of $\pm 2^{\circ} \mathrm{C}$ induced changes in gas
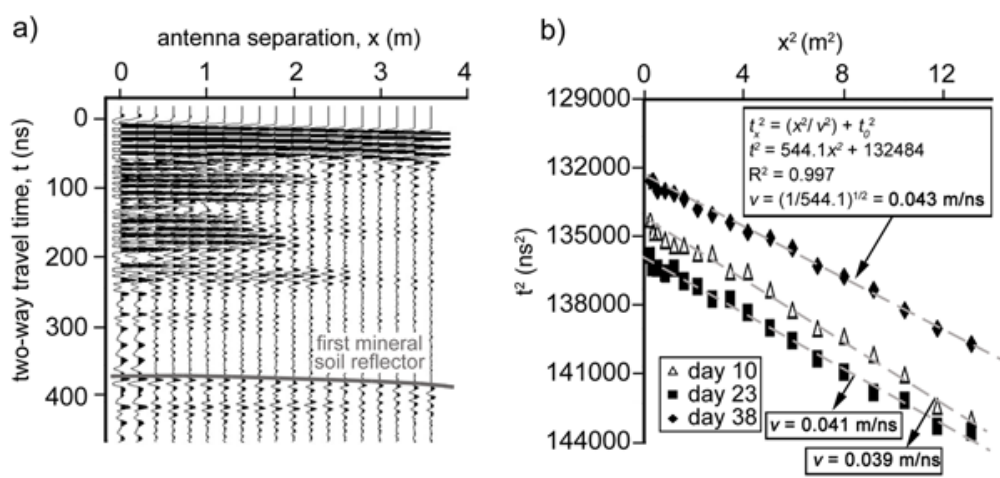

Figure 2. (a) GPR CMP gather showing reflected wavelet corresponding to the peat-mineral soil interface. (b) GPR CMP gather $\left(\mathrm{CMP}_{2}\right)$ showing the fitting of NMO hyperbolas for days 10, 23, and 38, and differences in estimated EM velocities. 


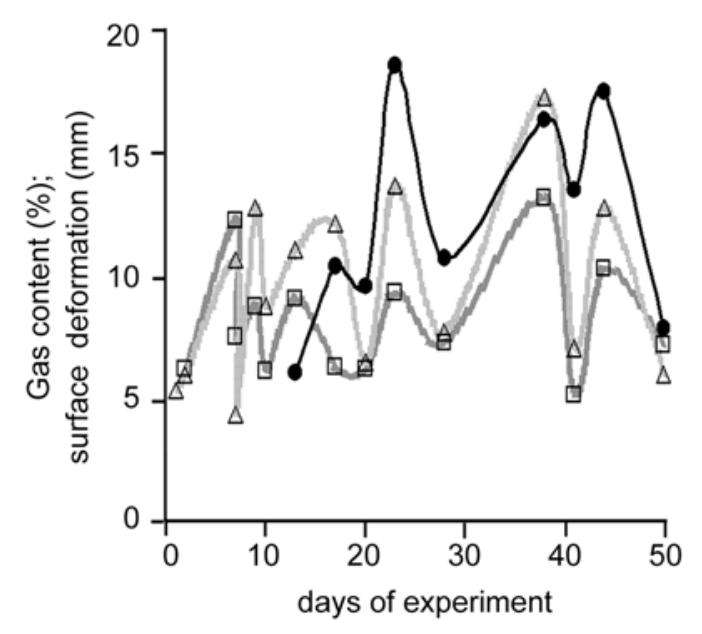

$\begin{array}{cll}\Delta-\text { gas content from CMP line 1 }\left(\mathrm{CMP}_{1}\right) & \text { Gas content assuming: } \\ \square-\text { gas content from CMP line 2( }\left(\mathrm{CMP}_{2}\right) & \text { EPEAT }=2 \\ \square-\text { relative change in surface elevation } & \text { aver. } \phi=92.2-92.7 \%\end{array}$

Figure 3. CRIM estimated volumetric gas content (\%) for CMP line $1\left(\mathrm{CMP}_{1}\right)$ and line $2\left(\mathrm{CMP}_{2}\right)$, and change in surface elevation (relative to day 10) for averaged elevation rod locations (see Figure 1) as a function of time.

content $< \pm 0.5 \%$; (3) constant water table, as measured water level variations up to $5 \mathrm{~cm}$ induced changes in gas content $< \pm 0.5 \%$; and (4) negligible effect of the air gap between GPR antennas and peat surface, as estimated changes in $t_{x}$ and $x$ as related to the EM wave angle of incidence induced changes in gas content $< \pm 0.5 \%$.

[8] Peat surface deformation was monitored throughout the experiment using elevation rods along the platform. Changes in rod length relative to a fixed datum established with a precision laser level fixed to the platform were recorded for a total of 25 rods equally spaced across the surface of the peat (estimated maximum measurement error $>0.0035 \mathrm{~m}$ ).

[9] Biogenic gas emissions in the field were estimated using a portable combustible gas detector (VRae) factorycalibrated for methane with a resolution of $500 \mathrm{ppm}$ of $\mathrm{CH}_{4}$. Although other approaches for $\mathrm{CH}_{4}$ detection are more sensitive and accurate (e.g., gas chromatography), the detector was solely used to obtain a semi-quantitative estimate of $\mathrm{CH}_{4}$ flux variations over the duration of the experiment. A static chamber approach was followed by measuring gas concentration in a $45 \mathrm{dm}^{3}$ chamber every 0.5 minutes for a 20 minute period, performing a linear regression of concentration versus time, and applying Henry's ideal gas law to estimate gas fluxes (Figure 1). Atmospheric pressure was measured in the field using a Solinst LTC Levelogger (Model 3001).

\section{Results}

[10] All CMP gathers collected at the study area resolved a distinct reflector between 360-390 ns (see example in Figure 2a), interpreted as the peat-mineral soil interface (and confirmed by direct core sampling, Figure 1). Although other reflectors are also distinct (e.g., 90,160 or $220 \mathrm{~ns}$ in Figure 2a) within the profile, these will not be considered in this study. EM travel times can be picked accurately from this mineral soil reflector to measure the average NMO velocities through the entire peat column (reflector dipping $<4^{\circ}$, as calculated from mineral soil direct sampling). Figure $2 \mathrm{~b}$ shows the sensitivity of these NMO velocities with time for days 10,23, and 38 of the experiment. Overall variations in $\mathrm{NMO}$ velocities for all data within the time frame of this study ranged between $0.038-0.045 \mathrm{~m} / \mathrm{ns}$, and are consistent with the laboratory results obtained by Comas and Slater [2007].

[11] Variations in biogenic gas accumulation over time at the study area are evident in both estimated NMO velocities and surface deformation data. Figure 3 shows the gas content as a function of time (days of experiment) for CMP gathers (lines $\mathrm{CMP}_{1}$ and $\mathrm{CMP}_{2}$, in Figure 1) obtained from application of the CRIM (equation 2), using $\varepsilon_{r(s)}=2$, $\varepsilon_{r(w)}=80, \alpha=0.35$, and average porosity between 92.2 and $92.7 \%$ (as estimated from changes in surface deformation, e.g., Kellner et al. [2005]). Although CMP line 2 generally shows smaller gas content estimates, relative gas content changes in both CMP gathers correspond. Variations in estimated gas content range between $4-17 \%$ after application of CRIM. The averaged relative change in surface elevation (from day 10, when proper readings were acquired) as a function of time at elevation rod locations (Figure 1) reveal a strikingly similar trend to the EM data (Figure 3). Periods of relative increase (e.g., day 17, 23, 38 and 44) and decrease (e.g., day 20, 28, 41 and 50) in surface deformation coincide with periods of increased and decreased gas content as estimated with GPR.

[12] Periods of increased and decreased GPR gas content estimated from CRIM, correspond with high and low gas flux (Figure 4) and surface deformation measurements (Figure 3). Gas flux values compare well with other reported values using other methods to estimate ebullition fluxes (e.g., Strack et al. [2005] reported methane flux values exceeding $1 \mathrm{~g} \mathrm{CH}_{4} / \mathrm{m}^{2} / \mathrm{d}$ in a floating mat site in Canada using a static chamber; and Rosenberry et al. [2003]
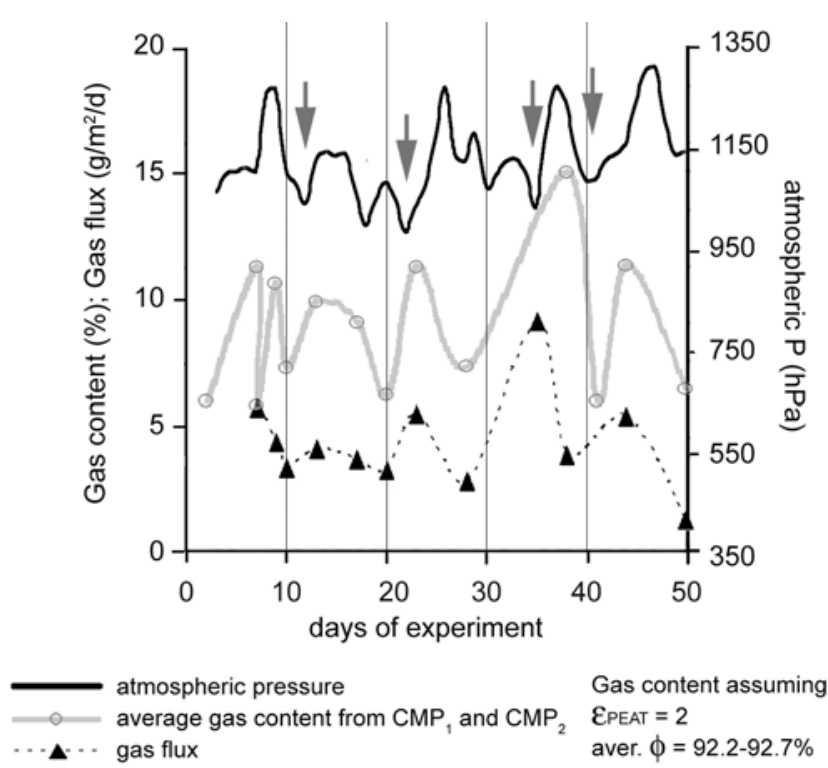

Figure 4. Atmospheric pressure, gas flux, and averaged gas content for CMP lines as a function of time. Arrows indicate correspondence between falling atmospheric pressure and gas flux increase. 
reported gas flux values exceeding $11 \mathrm{~g} \mathrm{CH}_{4} / \mathrm{m}^{2} / \mathrm{d}$ using hydraulic head differences). Periods of falling atmospheric pressure also correlate with certain periods of increased gas flux (as noted by arrows in Figure 4). Decreases in atmospheric pressure (e.g., during days 13, 23, 35, and 40) match periods of increased gas flux and overall increases in gas content within peat soil as estimated from GPR.

\section{Discussion}

[13] Application of the CRIM model (equation 2) to the EM wave velocities obtained from the CMP gathers implies that changes in velocity result from significant variation in volumetric gas content within a $5.8 \mathrm{~m}$ thick peat column. Surface deformation and gas flux results are also consistent with this trend, showing increases and decreases in both peat surface deformation and biogenic gas ebullition consistent with similar changes in GPR estimated gas content. Estimated temporal changes in total biogenic gas content (up to $17 \%$ ) and evolution (up to $13 \%$ total change, Figure 3) exhibits many similarities with previous investigations utilizing other methodologies (up to $19 \%$ in total biogenic gas content and 17\% total change [e.g., Strack et al., 2005; Rosenberry et al., 2006]. Differences in temporal patterns in gas content within GPR transects (lines $\mathrm{CMP}_{1}$ and $\mathrm{CMP}_{2}$ in Figure 3) may be indicative of changes in the spatial distribution of biogenic gas. Gas content measured along line $\mathrm{CMP}_{1}$ was generally greater than along $\mathrm{CMP}_{2}$ (Figure 3). This tendency is consistently stronger during periods of high gas content (e.g., Day 9, 17, 23, 38, and 44 in Figure 3, showing $4 \%$ gas content differences). We attribute these changes to: (1) the anisotropy and/or heterogeneity of peat soils (as demonstrated by others, e.g., Beckwith et al. [2003]), that may induce differences in pore-size distribution or other physical properties, and thus change the ability of peat to trap and release gas; and/or (2) differences in the availability of labile carbon that is used as substrate by methanogens and other microbes [e.g., Baird et al., 2004].

[14] One of the most striking observations from the GPR results is the rapid shift in gas content. This trend is consistent with similar GPR-based laboratory studies [Comas and Slater, 2007]. Gas content does not steadily accumulate over long periods of time but shifts on a weekly basis, suggesting that FPG quickly accumulates in the peat and is released to the atmosphere. This trend is also consistent with atmospheric pressure (Figure 3) and gas flux (Figure 4) results.

[15] Total changes in surface elevation (up to $20 \mathrm{~mm}$, Figure 3) show a very consistent trend relative to gas content estimated from GPR, but seem conservative when compared to changes in surface elevation reported for some field studies [Glaser et al., 2004]. Previous studies also suggest that gas volume estimated from surface deflection measurements were too small [e.g., Price, 2003], and attributed the anomalous measurements to displacement of pore water by gas (and thus inducing changes in the water level) without inducing a change in peat volume. A similar process may be responsible for the suppressed surface deformation changes presented here.

[16] Our results are also consistent with recent work suggesting that barometric pressure variation drives ebullition [e.g., Glaser et al., 2004; Tokida et al., 2005a; Kellner et al., 2006]. Decreases in atmospheric pressure are associated with certain events showing an increase in gas flux (arrows in Figure 4). Although these events seem to generally be followed by a decrease in gas content within the peat matrix, the trend is not fully consistent showing delays in decreased gas content (e.g., Day 35, most likely associated to the limited data density). We suggest our results show release of biogenic gas associated with two different processes: (1) ebullition events related to episodes of low atmospheric pressure (e.g., Day 13, 23, 35, and 40 in Figure 4); and (2) ebullition events (e.g., Day 7, 20, and 50 in Figure 4) related with processes other than barometric pressure, such as accumulation and release of gas bubbles associated with semi-confined layers. Distinct reflectors within the GPR profiles (e.g., at 90, 160 or $220 \mathrm{~ns}$ in Figure 2a) may then be indicative of such layers.

[17] Changes in biogenic gas content estimated with GPR can be used to quantitatively estimate methane releases during single ebullition events at Caribou Bog. Assuming $54 \%$ methane fraction for the gas phase [e.g., Glaser et al., 2004] and applying the ideal gas law, the methane released during three events correspond to: $105 \mathrm{~g} / \mathrm{m}^{2}$ between Day $17-20 ; 192 \mathrm{~g} / \mathrm{m}^{2}$ between Day $38-41$; and $63 \mathrm{~g} / \mathrm{m}^{2}$ between Day $44-50$. Values of $10 \mathrm{~g} / \mathrm{m}^{2}, 11 \mathrm{~g} / \mathrm{m}^{2}$, and $20 \mathrm{~g} / \mathrm{m}^{2}$ methane released respectively during the same events are estimated from the gas flux data. Although divergence between these estimates is most likely related to scale differences between the two measurements, and considering the thickness of the peat deposit at Caribou Bog, values are in agreement with methane loss during ebullition events reported by others [e.g., Glaser et al., 2004].

[18] Our work shows that EM travel time measurements in the field offer unique, non-invasive, means to explore gas dynamics in peat soils. Changes in the two-way travel time from the surface to prominent reflectors (e.g., the peatmineral soil horizon) allow estimation of average biogenic gas content. This approach could be applied to other reflectors within the peat column in order to investigate the evolution of biogenic FPG with depth and/or the presence of semi-confining layers as proposed by others. Unlike previously applied probe-based approaches, potential preferentially gas release pathways as the result of probe insertion are completely avoided.

\section{Conclusions}

[19] Rapid variation in gas content and associated gas release within an in-situ peat column is evident from GPR, surface deformation and gas flux data presented in this study, and shows a high level of consistency. We demonstrated that EM travel time measurements offer a more accurate and entirely non-invasive way of investigating biogenic gas without risking alteration of gas dynamics, and at a scale appropriate for determining average values for the peat column. Our in situ measurements at Caribou Bog show many consistencies with previous studies of gas dynamics in peat soils including biogenic gas content, evolution and amount of released methane, and how certain processes (e.g., changes in atmospheric pressure) may drive ebullition events. With this approach spatial distribution and evolution of biogenic gas content with depth can be readily investigated. 
[20] Acknowledgments. This material is based upon work supported by the National Foundation under grant 0510370 . Graduate students Jay Nolan and Mike O’Brien from Rutgers University, and Zach Tyczka from University of Maine provided valuable field support. We also thank two anonymous reviewers for their suggestions to enhance the quality of this manuscript.

\section{References}

Baird, A. J., C. W. Beckwith, S. Waldron, and J. M. Waddington (2004), Ebullition of methane-containing gas bubbles from near-surface Sphagnum peat, Geophys. Res. Lett., 31, L21505, doi:10.1029/2004GL021157.

Beckwith, C. W., and A. J. Baird (2001), Effect of biogenic gas bubbles on water flow through poorly decomposed blanket peat, Water Resour. Res., 37(3), 551-558.

Beckwith, C. W., A. J. Baird, and A. L. Heathwaite (2003), Anisotropy and depth-related heterogeneity of hydraulic conductivity in a bog peat. I: Laboratory experiments, Hydrol. Processes, 17, 89-101.

Charman, D. J. (2002), Peatland Systems and Environmental Change, 331 pp., John Wiley, Hoboken, N. J.

Comas, X., and L. Slater (2007), Evolution of biogenic gasses in peat blocks inferred from non-invasive dielectric permittivity measurements, Water Resour. Res., doi:10.1029/2006WR005562, in press.

Comas, X., L. Slater, and A. Reeve (2005a), Spatial variability in biogenic gas accumulations in peat soils is revealed by ground penetrating radar (GPR), Geophys. Res. Lett., 32, L08401, doi:10.1029/2004GL022297.

Comas, X., L. Slater, and A. Reeve (2005b), Geophysical and hydrological evaluation of two bog complexes in a northern peatland: Implications for the distribution of biogenic gases at the basin scale, Global Biogeochem. Cycles, 19, GB4023, doi:10.1029/2005GB002582.

Fechner-Levy, E. J., and H. F. Hemond (1996), Trapped methane volume and potential effects on methane ebullition in a northern peatland, Limnol. Oceanogr., 41, 1375-1383.

Glaser, P. H., J. P. Chanton, P. Morin, D. O. Rosenberry, D. I. Siegel, O. Ruud, L. I. Chasar, and A. S. Reeve (2004), Surface deformations as indicators of deep ebullition fluxes in a large northern peatland, Global Biogeochem. Cycles, 18, GB1003, doi:10.1029/2003GB002069.

Gorham, E. (1991), Role in the carbon cycle and probable responses to climatic warming, Ecol. Appl., 1, 182-195.

Greaves, R. J., D. P. Lesmes, J. M. Lee, and M. N. Toksöz (1996), Velocity variations and water content estimated from multi-offset, groundpenetrating radar, Geophysics, 61(3), 683-695.

Hubbard, S. S., K. Grote, and Y. Rubin (2002), Mapping the volumetric soil water content of a California vineyard using high-frequency GPR ground wave data, Leading Edge, 21(6), 552-559.

Huisman, J. A., S. S. Hubbard, J. D. Redman, and A. P. Annan (2003), Measuring soil water content with ground penetrating radar: A review, Vadoze Zone J., 2, 476-491.
Kellner, E., J. M. Waddington, and J. S. Price (2005), Dynamics of biogenic gas bubbles in peat: Potential effects on water storage and peat deformation, Water Resour. Res., 41, W08417, doi:10.1029/2004WR003732.

Kellner, E., A. J. Baird, M. Oosterwoud, K. Harrison, and J. M. Waddington (2006), Effect of temperature and atmospheric pressure on methane $\left(\mathrm{CH}_{4}\right)$ ebullition from near-surface peats, Geophys. Res. Lett., 33, L18405, doi:10.1029/2006GL027509.

Neal, A. (2004), Ground-penetrating radar and its use in sedimentology: Principles, problems and progress, Earth Sci. Rev., 66, 261-330.

Price, J. S. (2003), Role and character of seasonal peat soil deformation on the hydrology of undisturbed and cutover peatlands, Water Resour. Res., 39(9), 1241, doi:10.1029/2002WR001302.

Romanowicz, E. A., D. I. Siegel, J. P. Chanton, and P. H. Glaser (1995), Temporal variations in dissolved methane deep in the Lake Agassiz peatlands, Minnesota, Global Biogeochem. Cycles, 9, 197-212.

Rosenberry, D. O., P. H. Glaser, D. I. Siegel, and E. P. Weeks (2003), Use of hydraulic head to estimate volumetric gas content and ebullition flux in northern peatlands, Water Resour. Res., 39(3), 1066, doi:10.1029/ 2002 WR001377.

Rosenberry, D. O., P. H. Glaser, and D. I. Siegel (2006), The hydrology of northern peatlands as affected by biogenic gas: Current developments and research needs, Hydrol. Processes, 20, 3601-3610.

Strack, M., E. Kellner, and J. M. Waddington (2005), Dynamics of biogenic gas bubbles in peat and their effects on peatland biogeochemistry, Global Biogeochem. Cycles, 19, GB1003, doi:10.1029/2004GB002330.

Tokida, T., T. Miyazaki, and M. Mizoguchi (2005a), Ebullition of methane from peat with falling atmospheric pressure, Geophys. Res. Lett., 32, L13823, doi:10.1029/2005GL022949.

Tokida, T., T. Miyazaki, M. Mizoguchi, and K. Seki (2005b), In situ accumulation of methane bubbles in a natural wetland soil, Eur. J. Soil Sci., $56,389-395$.

Waddington, J. M., T. J. Griffis, and W. R. Rouse (1998), Northern Canadian wetlands: Net ecosystem $\mathrm{CO}_{2}$ exchange and climatic change, Clim. Change, 40, 267-275.

Wharton, R. P., G. A. Hazen, R. N. Rau, and D. L. Best (1980), Advancements in electromagnetic propagation logging, SPE Paper 9041-MS, Soc. Petr. Eng., Richardson, Tex.

X. Comas and A. Reeve, Department of Earth Sciences, University of Maine, Bryland Global Sciences Center, Orono, ME 04469-5790, USA. (xcomas@pegasus.rutgers.edu)

L. Slater, Department of Earth and Environmental Sciences, Rutgers University, 101 Warren Street, Room 137, Smith Hall, Newark, NJ 07102, USA. 